This document is an electronic post-print of an article published in Slavic \& East European Information Resources (SEEIR). Typographical errors have been corrected in this version. Cites to this article should be made to the version published in SEEIR.

Giullian, J. C. (2016). Aspects of Diversity in ASEEES National Conferences as a Reflection of the Field of Slavic and Eurasian Studies in North America: Case Studies of Gender, Location, Discipline, and Institution. Slavic and East European Information Resources, 17(4), 191-214. DOI:10.1080/15228886.2016.1246301 http://dx.doi.org/10.1080/15228886.2016.1246301

\title{
Aspects of Diversity in ASEEES National Conferences as a Reflection of the Field of Slavic and Eurasian Studies in North America: The Case of Gender, Location, Discipline, and Institution
}

\begin{abstract}
This article is a series of four case studies that investigate diversity in Slavic and Eurasian ( $S \& E$ ) studies viewed through the lens of participation in national conferences of the Association of Slavic, East European, \& Eurasina Studies (ASEEES). The case studies are based on data extracted from ASEEES convention programs 1964-2014. Four categories are considered: gender diversity of conference participants, diversity of ASEEES conference locations, diversity of conference sessions by discipline, and diversity of institutions represented at ASEEES conventions. Over the past five decades gender diversity of ASEEES conference session participants gradually advanced toward parity. Whereas in 1964 nearly 95 percent of the participants were men; in 2014 women comprised a slight majority (50.2\%) of conference session participants. In contrast, diversity in the location of ASEEES national conventions has declined in recent years as the Association has evolved. Whereas the disciplines of history, political science, and language, literature, and linguistics continue to represent a combined majority (70\%) of ASEEES sessions; anthropology and sociology have experienced the most growth; and library and information science remained constant in recent years. ASEEES conference session participants come from a wider range of institutions than in the past, and institutions with Title VI National Resource Centers (NRCs) continue to have a strong presence at the ASEEES national conventions.
\end{abstract}

Keywords: Association of Slavic, East European, \& Eurasian Studies, ASEEES, conference programs, Committee on Libraries and Information Resources, diversity, gender, men, women, geographic, institutional, academic discipline, location, Title VI National Resource Center, librarianship, library science. 


\section{Introduction}

Diversity can be a charged term for some people. Related words include diverge, divergence, and maybe even divide. The term tends to emphasize differences, which has value in and of itself, but because diversity can be a charged term, I like to think of diversity in terms of variety. It is variety that I find interesting. Inclusivity is a term that I like as well because it emphasizes togetherness, belonging, including lots of things, people, data, etc. Scholars come together at national conferences of the Association of Slavic, East European, and Eurasian Studies (ASEEES) because they share an interest in Slavic and Eurasian (SE) studies. It is nice to feel included, welcomed, appreciated, and valued. That's how I felt when I entered the field of Slavic librarianship. My library colleagues who attend ASEEES are kind, warm, helpful, diverse in background and knowledge, and at the same time accepting, welcoming, and encouraging, mixed with a pleasant sense of humor as needed. As a new colleague this made a big difference in my development as a library specialist; so I express appreciation to my library colleagues for their spirit of inclusivity in welcoming the first, to my knowledge, Mormon Slavic librarian to their ranks.

Diversity of collections has been a dominant theme for discussion among librarians at the annual conventions of the Association for Slavic, East European, and Eurasian Studies (ASEEES) over the past decade (see Figure 5). ${ }^{1}$ Comparisons, evaluations, and descriptions of distinctive collections have been discussed broadly at recent ASEEES conferences ${ }^{2}$ and have been the subject of recent articles published in SEEIR. ${ }^{3}$ In an effort expand the discussion of diversity beyond collections and to engage a broader audience of ASEEES members, beyond the librarians, I changed focus of this project from the diversity of collections to the diversity of ASEEES conference participation. This study is an attempt to capture a series of snapshots or cross-sections of session participation in ASEEES national conventions, as a gauge of how some aspects of diversity of Slavic and Eurasian studies had changed over time. ${ }^{4}$

One might ask: Why ASEEES? First, ASEEES, more than any other Slavic and Eurasian studies association represents a cross-section of Slavic and Eurasian (S\&E) studies in North

\footnotetext{
${ }^{1}$ Prior to 2010 the name of the association was American Association for the Advancement of Slavic Studies (AAASS).

${ }^{2}$ A few examples include: "Collection Matters: Managing, Measuring and Assessing Slavic Library Collections," 2007; "Hidden Library Treasures," 2008; "Pacific Rim Slavic Bibliographers and Their Collections," 2010; "Collections in our Slavic and East European Diaspora: Preserving and (Re) interpreting Collective Memory," 2013; "Subject Analysis of Slavic Materials after the Fall of the Berlin Wall," 2014.

${ }^{3}$ Two examples include: Michael Neubert and Michael Brewer. “Identifying Holdings Unique to Your Library's Collections Using Worldcat. SEEIR, v. 7, n. 4 (April 2007): p. 115-121. Masha Stepanova. "Analysis of the Russian, East European, and Eurasian Studies Collection at Miami University." SEEIR, v. 9, n. 2 (August 2008): p. 92-114. ${ }^{4}$ This article is an expansion of a roundtable presentation that I gave at the national convention of the Association for Slavic, East European, and Eurasian Studies (ASEEES). The title of the roundtable was "Inclusivity and Academic Diversity in Slavic, East European, and Eurasian Studies." Although the project was initially conceived as an exploration in the diversity of Slavic and Eurasian (S\&E) collections, I wanted to explore the topic more broadly and find an angle that would appeal to a broader audience of ASEEES members, beyond the network of Slavic librarians.
} 
America. ${ }^{5}$ Second, ASEEES data is publicly available in the organization's national convention programs. Because this data was prepared for a panel on diversity at the ASEEES national convention, it made sense to limit the analysis to ASEEES data. Third, ASEEES represents a broader range of disciplines. A data set for all of S\&E studies does not exist, and, it was implausible to survey the entire profession. Even a survey sent out to members of the profession would be at best an imperfect and probably unrepresentative sample. The next step was to determine which categories of data to examine. Based on data from the conference programs, this study analyzes the distribution of ASEEES session participants by gender (1964-2014), location (1964-2018), academic discipline (2012-2015), and to a limited degree by institution (20122015). The longitudinal data for each category was limited by what is available in the ASEEES national convention programs, both printed and online; hence longitudinal is better or deeper for some of the case studies than for others.

\section{Gender Diversity ${ }^{6}$}

The first criteria to be examined in this study is gender diversity. The study tracks the distribution of men and women who participated in AAASS/ASEEES conferences since the founding of the Association in 1964. Rather than analyze every year of conference participation, the study used a sample, selecting programs at 10-year intervals (1964, 1975, 1984, 1994, 2004 and 2014). ${ }^{7}$ The index of conference participants in the back of the conference programs served as the source of data for calculating the number of male and female conference participants from 1964-2014; however, since there was no index in the programs from 1964 and 1975, participant names listed in program of sessions were analyzed. ${ }^{8}$. Whereas conference programs 2004-present were available on the ASEEES website, copies of previous programs were obtained through interlibrary loan and by special request to Slavic librarian colleagues. ${ }^{9}$

The gender distribution of conference participants is presented the figures below. Figures 1 and 2 present snapshots of the gender distribution of ASEEES session participants across five

\footnotetext{
${ }^{5}$ What about AATSEEL (American Association of Teachers of Slavic and East European Languages)? Unfortunately I was unable to find data for AATSEEL that was as readily available. Moreover, AATSEEL has a limited scope, focusing on language, literature, linguistics, \& culture.

${ }^{6}$ In this study gender diversity is defined strictly as the number of males relative to females base on names as an indicator of gender. Gender in terms lesbian, gay, bisexual, transsexual, questioning, asexual, or intersexual are not included part of this study.

${ }^{7}$ Data from 1975 data was used instead of data from 1974 because the 1974 conference held in Banff, Canada was an international conference sponsored by four organizations of professionals in Slavic studies: The American Association for the Advancement of Slavic Studies, the British Universities Association of Slavists, The British National Association for Soviet and East European Studies, and The Canadian Association of Slavists.

${ }^{8}$ As stated in some of the programs (e.g., 2007-2009), "[the] index includes only those panel and roundtable participants who have pre-registered." The convention programs differ slightly from the actual session participants because some sessions are canceled and some participants are unable to attend their sessions.

${ }^{9}$ Ironically, when I sent out an email to colleagues at the University of Kansas, I discovered that one faculty member had recently discarded 20-30 years of convention programs-an unfortunate loss for KU Libraries. Fortunately, I was able to get copies through interlibrary loan. A special thanks goes to Kit Condill (U. Illinois, Urbana-Champaign) Wookjin Cheun (Indiana U., Bloomington), June Farris (Chicago U.), Cathy Zeljak (George Washington U.), and Kirill Tolpygo and Angelia Graff (U. North Carolina, Chapel Hill) for their assistance in obtaining copies of programs.
} 
decades (1964, 1975, 1984, 1994, 2004 and 2014).$^{10}$ The data indicate that only a handful (5.6\%) of participants listed in the 1964 AAASS program were female. A decade later, in 1974, the number of women (14.7\%) compared to men (85.3\%) had grown by $9 \%$. Subsequent decades witnessed steady growth (about $12 \%$ per decade) until by 2004 the picture had changed dramatically, such that nearly half of all conference participants were women (47.9\%). The tipping point occurred just last year in 2014 when the number of women (732 or 50.2\%) listed in the conference program index surpassed the number of men (728 or 49.8\%) by a margin of four participants (Figure 2). For the first time in the Association's history there was almost an equal number of men and women taking part in the annual convention. ${ }^{11}$ The comparable numbers of

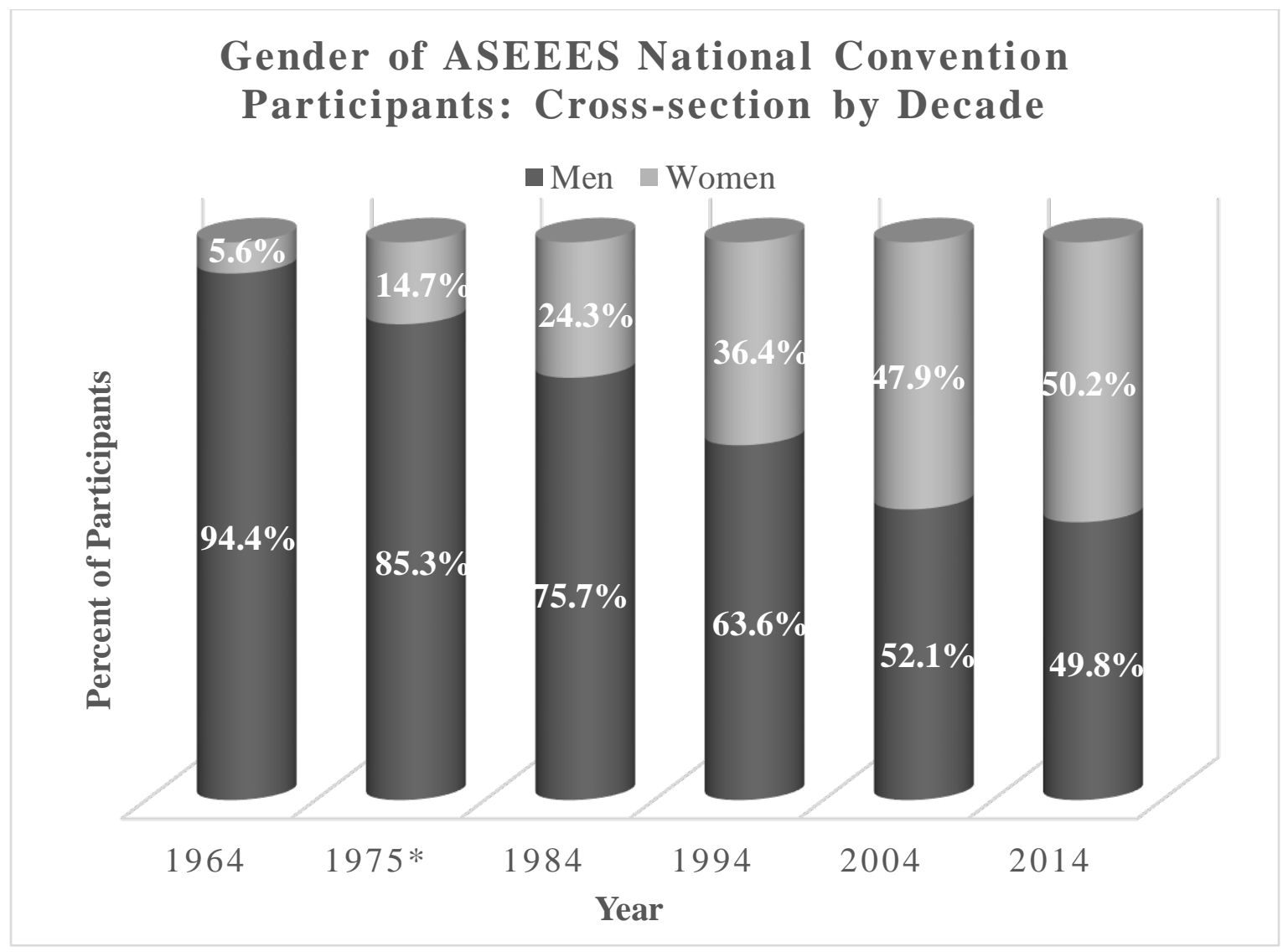

Figure 1: Gender and Number of Session Participants at ASEEES National Conventions: Cross-section by Decade (*See note 7)

\footnotetext{
${ }^{10}$ For names that appeared to be ambiguous, the author located information about the specific individual. This information was usually an image or pronoun in the individual's academic profile or biography. In most cases, this strategy was successful. In the few cases where the individual could not be located, a web search and image search were used to determine the gender of the first name. In rare cases the author consulted colleagues.

${ }^{11}$ This data is based upon the 2014 ASEEES National Convention program. The data extracted from the conference programs differ slightly from the number of participants who actually attended conference because some people on the program were unable to attend the conference.
} 
men and women listed in the 2014 ASEEES national convention program serves as one indicator of increasing gender parity within the field. Although the rate of growth in the percentage of female participants compared to male participants has slowed, there is no reason to believe that the trend will not continue. A broader question is whether ASEEES convention participation data reflect the gender distribution in the field of Slavic and Eurasian studies in North America. ASEEES membership data suggests that it does. For example, data from surveys distributed to ASEEES members by the ASEEES Committee on the Status of Women (CSW) in 1999 and 2012 show that the gender gap declined from 8\% to 4\% from 1999 to 2012, such that by 2012 men comprised $48 \%$, and women $44 \%$; $7 \%$ did not report gender. ${ }^{12}$

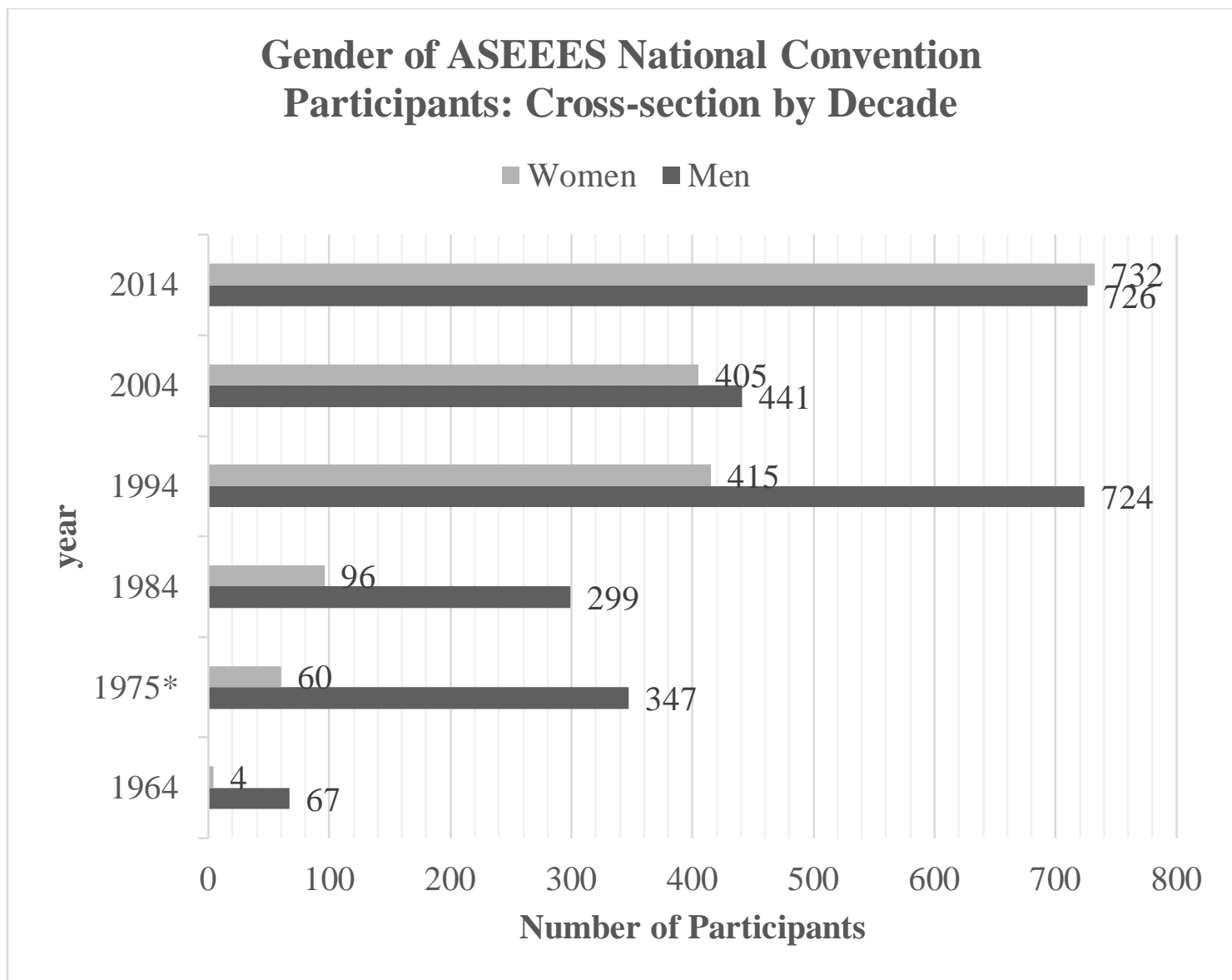

Figure 2: Gender and Number of Session Participants at ASEEES National Conventions: Cross-section by Decade (*See note 7 )

\footnotetext{
${ }^{12}$ See Laura E. Schlosberg, and Christine D. Worobec. "Lowering the Glass Ceiling: A Gender Profile of Professionals in Slavic Studies, NewsNet, v. 42, n. 2 (March 2002): p. 13-19; and Paula A. Michaels, Karen Petrone, Laura Schlosberg, Heather Tidrick, and Christine D. Worobec. "Making Strides: Gender Equity in the Slavic Studies Profession. NewsNet, v. 54, n. 2 (March 2014): p. 1.
} 
Although conference participation represents only one aspect of gender diversity in Slavic and Eurasian studies, this aspect is significant because it represents a level of active participation among not only established, practicing professionals ${ }^{13}$ in S\&E studies but also among graduate students. ${ }^{14}$ Graduate student represents the future of the field, and even though it is impossible to cull graduate student data from the conference programs, one would expect the distribution of graduate students listed in the ASEEES programs to favor female graduate students given the growth in female participants overall. ${ }^{15}$ A different data point can be used to capture the demographic trend among the graduate student population by looking at those who were recently hired. For example, new faculty hires in Slavic languages and literatures (SLL) departments at 30 universities across North America also show an influx of women into tenure-track positions. ${ }^{16}$ According to data compiled from departmental websites, women (28) outnumber men (13) more than 2 to 1 when it comes to recent faculty hires at the rank of assistant professor. ${ }^{17}$ Local data tell a similar story. During the past six years women comprised 3 of 5 faculty hires in the SLL department at the University of Kansas (KU) and 3 of 5 new faculty hires at the Assistant Professor level in KU's Center for Russian, East European, and Eurasian Studies (CREES).

While gender diversity is one thing, gender equity represents much more. The data in this study suggest that the field of Slavic and Eurasian studies has demonstrated significant movement toward gender diversity, in terms of the ratio of women to men, especially during the past two decades. Gender equity, on the other hand, involves many more criteria such as rank, salary, status, position of leadership, graduate school experience, and so on. Previous surveys on gender equity in S\&E studies were conducted in $1999^{18}, 2007,{ }^{19}$ and $2012^{20}$ by the ASEEES Committee on the Status of Women (CSW). Data from both the 1999 and the 2012 surveys demonstrate that women continue to make significant gains in S\&E studies. For example, women fare well on the

\footnotetext{
${ }^{13}$ For example, professors, lecturers, teachers, librarians, archivists, museum curators, independent scholars, book vendors, members of scholarly societies, government specialists, and other professionals.

${ }^{14}$ Unfortunately the data do not include the career status of session participants (e.g. professor, lecturer, teacher, librarian, graduate student, exhibitor, etc.).

${ }^{15}$ The pattern may be a function of time and aging. In the earlier decades (1964, 1975, 1984, and 1994), men represented a majority of conference participants. As time passed and people aged, more men than women retired and stopped participating in ASEEES conference sessions. Hence, the exiting male participants were gradually replaced by more women attending the conference.

${ }^{16}$ The sample includes universities who belong to the S\&E library consortia in North America: Pacific Coast Slavic \& East European Library Consortium (http://intranet.library.arizona.edu/users/brewerm/pacslav/members.html), Midwest Slavic \& Eurasian Library Consortium (https://midslav.wordpress.com/mbrs), and the East Coast Consortium of Slavic Library Collections (http://www.eccslavic.org).

${ }^{17}$ Most new hires at the rank of assistant professor tend to be recent graduates (e.g., within the past six years). ${ }^{18}$ See Laura E. Schlosberg, and Christine D. Worobec. "Lowering the Glass Ceiling: A Gender Profile of Professionals in Slavic Studies, NewsNet, v. 42, n. 2 (March 1999): p. 13-19. Natasha Kolchevska also provides a brief summary of the 1999 survey results in "Gender and Slavic Studies: Overview and Goals for the Future." NewsNet, v. 45, n. 5 (October 2005): p. 3-4.

19 "Analysis of the 2007 survey results was never published." See endnote 1 on p. 3 in Paula A. Michaels, Karen Petrone, Laura Schlosberg, Heather Tidrick, and Christine D. Worobec. "Making Strides: Gender Equity in the Slavic Studies Profession. NewsNet, v. 54, n. 2 (March 2014): p. 1-4.

${ }^{20}$ Ibid.
} 
job market for tenure-track positions even though some inequity persists with regard to salaries in tenured and tenure-track positions. Like the CSW data, a cross-section of ASEEES conference participation over the past five decades points to significant gains among women in the field. These data suggest that ASEEES conference participation could serve as one metric for gauging the evolution of the demographic landscape of the field of Slavic and Eurasian studies in North America as a whole.

\section{Geographic Diversity}

This section explores the diversity of ASEEES annual convention locations, compares the number of participants at annual AAASS/ASEEES conferences by location from 1964-2015, and looks for a potential correlation between conference participation and conference location. ${ }^{21}$ In recent years, the geographical diversity of ASEEES annual convention sites has decreased. Whereas 22 different cities hosted the convention from 1964-2005, during the past decade (20062015) only six cities have played host; ${ }^{22}$ and some of the same cities are slated to continue hosting the conference in future years. ${ }^{23}$ In terms of location by region, six of the last ten conferences and nearly half (23) of all (48) conferences since 1964 were hosted on the east coast. ${ }^{24}$

Among the many factors that influence an individual's decision to attend the ASEEES convention, geographical location is one factor that is constant for all participants. ${ }^{25}$ Data in Figure 3 show conference participation from 1964-2015 based on the number of participants listed by name in printed conference programs. ${ }^{26}$ At the writing of this article, 46 of the 47 conference programs were analyzed, missing only the 1976 St. Louis, MO convention program, which could not be located. Analysis of data in Figure 3 (See Appendix) suggests three stages of development in conference participation, beginning with a period of steady growth from inception of the convention in 1964 through the mid-1990s; followed by nearly a decade of decline; and finally a rapid yet volatile period of growth, in which the number of participants reached a new all-time high of 1780 participants at the 2015 convention in Philadelphia, PA.

The first stage, 1964-1995, included 28 conventions over 31 years and witnessed steady growth from 71 to 1269 participants with only a few anomalies. The incremental growth from 1964-1995 suggests that location was not a major factor influencing conference participation,

\footnotetext{
${ }^{21}$ This case study does not discuss how convention sites have been and are currently being determined by the Association.

${ }^{22}$ Boston, MA (2), New Orleans, LA (2), Philadelphia, PA (2), Washington, DC (2), Los Angeles, CA (1), and San Antonio, TX (1).

${ }^{23}$ Washington D.C. (2016), Chicago, IL (2017), Boston (2018)

${ }^{24}$ East (23) Midwest (6), South (8), West (9), Canada (2). In the recent past, the ASEEES national convention has not been hosted in the Midwest, in spite of the fact that Midwestern universities serve as hubs of scholarly activity in Slavic and Eurasian studies. Midwestern universities boast a majority of federally funded National Resource Centers dedicated to Russia, Eastern Europe, and Eurasia, which constitute a high concentration of scholars who study the region. This point will be discussed in greater detail later on in this article.

${ }^{25}$ Other factors might include funding, tenure requirements, illness, or natural disasters. However, it seems reasonable to presume that these factors, with the exception of natural disasters, will be more or less constant. ${ }^{26}$ Data in Figure 3 will differ from the number of attendees who registered for the conference, since the conference program only lists session participants.
} 
except in a few cases, which are discussed below. For example, there was a significant drop in the number of participants when New York City hosted the conference, in 1973 and 1984. Although one might expect New York City (NYC), with its many attractions, to draw a large number of people to the conference, the data suggests otherwise. Anecdotally, some ASEEES members have commented that the Association no longer holds the convention in New York City because lodging is too expensive, which would explain why the convention has not returned to NYC since 1984. Not only does Association revenue drop when the convention is held in NYC, but location's impact on participation undermines the main purpose of the conference, which is to bring scholars together to engage in open scholarly dialogue.

The other notable drop in participation during stage one took place at the convention held in Asilomar, CA (493). This drop in participation belongs to another apparent phenomenon, in which participation tends to drop when the convention moves to the west coast and rebounds when the convention moves back to the east coast. Consider the following three examples:

\begin{tabular}{|l|l|c|r|c|}
\hline Year & Location & Number of Participants & Change & Percent Change \\
\hline 1980 & Philadelphia, PA & 600 & & \\
\hline 1981 & Asilomar, CA & 493 & -107 & $-18 \%$ \\
\hline 1982 & Washington, DC & 583 & +90 & $+18 \%$ \\
\hline & & & & \\
\hline 1996 & Boston, MA & 1,247 & -91 & $-7 \%$ \\
\hline 1997 & Seattle, WA & 1,156 & +236 & $+20 \%$ \\
\hline 1998 & Boca Raton, FL & 1,392 & & \\
\hline & & & & \\
\hline 2009 & Boston, MA & 1,449 & -378 & $-26 \%$ \\
\hline 2010 & Los Angeles, CA & 1,071 & +230 & $+21 \%$ \\
\hline 2011 & Washington, DC & 1,301 & & \\
\hline
\end{tabular}

Figure 4: Convention Participation: East Coast vs West Coast.

According to data in Figure 4, participation fell mildly in Seattle, moderately in Asilomar (Monterey), CA, and sharply in Los Angeles, CA. Ironically, as the conference moved southward along the West Coast, the rate of decline steadily increased from $-7 \%$ in Seattle, to $-18 \%$ in Asilomar (Monterey) and finally to $-26 \%$ in L.A, where conference participation went into free fall. One would think that in November, the warmer southern coastal climates would attract more, but there must have been various other factors at work. In terms of location, maybe participants preferred the smaller, calmer resort ambience of Asilomar (Monterey) and the vibrant downtown, convenient transportation, and coastal attractions of Seattle, to the traffic, congestion, and brown cloud of Los Angeles.

As with NYC, participation data corroborates anecdotal evidence, which contends that participation drops at West Coast venues because of the longer distance and higher cost of 
traveling from the east region, where there is a higher concentration of ASEEES members. While the beautiful coastal resort may have attracted others, the higher cost of Asilomar's more remote location, far from a major airport, may have discouraged others. ${ }^{27}$ Especially disconcerting was the staggering 26 percent drop in participation at the Los Angeles convention, which brought with it a significant loss of revenue from the convention. Given the impact of conference participation on Association revenue, it is doubtful that the convention will return to L.A., and for good reason. Even though the sample of West Coast conventions is small, this pattern demonstrates the significant impact that geographical location can have on convention participation and underscores the importance of hosting the convention in a geographical location that encourages strong participation.

In addition to drops in participation, participation data also shows a series of spikes that took place across all three stages. For example, the first three decades witnessed two major spikes in participation, both of which took place in Washington, D.C. Although the nation's capital has typically attracted strong participation throughout the history of the convention, the astronomical spike in attendance in 1985 was a special case in which the AAASS combined with the International Committee for Soviet and East European Studies (ICEEES) to host the III World Congress for Soviet and East European Studies in Washington D.C. The Congress brought together 1,252 participants from 18 Slavic and East European studies associations worldwide, which was double the average participation over the previous six years and triple the number of participants who attended the convention in New York City the year before. ${ }^{28}$ The second spike in participation in 1988, also in Washington D.C., although smaller than the first, drew more participants $(1,053)$ than any other single AAASS convention in previous year. ${ }^{29}$ The number of participants attending the 1989 convention in Chicago, IL returned to a level that is more consistent with the pattern of steady growth during this first three decades of the convention.

After this long period of steady growth, convention participation headed into a decade of decline beginning, arguably, in 1996. The only anomaly during this decade was the sharp spike in participation at the balmy resort town of Boca Raton, FL in 1998. One could make the argument that it was precisely the balmy resort town of Boca Raton that attracted such a large group of participants and staved off the impending decline for one year. In 1999 conference participation went into free-fall at the convention in St. Louis, MO and remained well below 1,000 for seven years-a decline of Biblical proportions. After 32 years of feast, it was time for 7 years of famine. During this decade of decline and stagnation, the convention was held in nine different cities, with Boston playing host twice.

\footnotetext{
${ }^{27}$ Although Asilomar is adjacent to Monterey, CA, which has its own airport, flights into Monterey are limited and carry higher fares.

${ }^{28}$ The congress was sponsored by SEES Associations from Australia, Belgium, Britain, Canada, France, Germany, Greece, Ireland, Israel, Italy, Korea, Japan, Netherlands, New Zealand, Nordic countries, Southeastern Europe, and the United States.

${ }^{29}$ Although speculative, it seems plausible that the 1988 convention attracted many of the same international participants who had attended the convention in Washington, D.C. three years earlier.
} 
Like the congress in 1985, the 2011 convention in Crystal City, VA was another unprecedented anomaly but for a different reason. In 2001 the convention was scheduled to take place in the nation's capital in mid-November, only two months after the 9/11 terrorist attacks, one of which damaged the Pentagon and another of which targeted the U.S. Capitol or the possibly the White House. Following 9/11 the convention was moved to Crystal City, VA. The changed location, combined with heightened security for air travelers and also around Washington, D.C., discouraged many from attending the convention. The other low-point during the decade of general decline took place in Salt Lake City, UT, another location that seemed unpopular among Association members. ${ }^{30}$ In contrast, Denver, Colorado, the only other city in the Mountain West region to host the convention, turned out to be a popular venue during the period of stagnation. ${ }^{31}$ The most popular location during this period turned out to be Toronto, Ontario, Canada, which is surprising given the city's northern location as a host for a conference in November. However, the fact that Toronto was hosting the convention for the first time may have combine with the cosmopolitan atmosphere of city to attract strong participation. The only other convention to be held in Canada (Banff, 1974) also attracted strong participation. ${ }^{32}$ It is also possible that the conference in Toronto attracted a larger contingent of Slavists from Canada, who may have found it more convenient to attend the AAASS conference in their home country.

In 2006 the convention emerged from its 10-year recession, marking the third state in the evolution of convention participation. Returning to Washington, D. C. after an 11-year absence, the convention attracted close to double the number of participants $(1,107)$ from the previous year in Salt Lake City (715). Because Washington D.C. has drawn a larger number of participants in the past, compared to other host cities (see Figure 3, 1985, 1988, 1995, 2006, exception 1990), it seems plausible that the staying power of the nation's capital as an attractive destination was a significant factor in bringing conference attendance out of its decade-long slump. ${ }^{33}$ Following a slight drop at the New Orleans conference in 2014, participation again shot up in 2008 at the Philadelphia, PA convention. Then, in 2009 participation reached a new high of 1,449 session participants in Boston (Figure 4). From 2011-2013, session participation again rose steadily, reaching a new high in Boston $(1,636)$ in 2013. When the conference moved south to San Antonio, TX in 2014, session participation once again dropped. Figure 3 shows that conference participation decreases as the convention site moves west (e.g. to SLC and LA); whereas Boston $\left(1,449\right.$ and 1,636) ${ }^{34}$ drew the highest participation in 2009 and then again in 2013, followed by New Orleans which drew 1,348 participants in 2012. ${ }^{35}$

\footnotetext{
${ }^{30}$ Anecdotally, some members complained about the apparent deficiency of morning coffee at this venue.

${ }^{31}$ It must have been the coffee.

32 The 1974 conference in Banff was an international conference that brought together multiple Slavic studies associations. See note 7.

${ }^{33}$ Boston, MA had also been a strong performer, except for the conference in 2004; so there must have been other factors at work that accounted for lower participation.

${ }^{34}$ The potential for bad weather in Boston in November does not seem to have a negative impact on participation.

${ }^{35}$ Participation at the conference in New Orleans in 2007 might have been higher had it not been for Hurricane Katrina, which devastated the region in the spring of 2005.
} 
Although it would be impossible to measure all of the variables that impact conference session participation, location seems to be one factor that influences the number of participants. Changes in Association guidelines may have also contributed to the general overall increase in conference participation. In years past, ASEEES only accepted proposals for panels and roundtables, which excluded individuals who were unable to form a full panel. This policy would tend to be less advantageous to graduate students who may not have developed a network of colleagues with whom they could organize a panel. Recently ASEEES began accepting individual paper proposals and grouping them into panels. This change made it easier for everyone, including graduate students, to present their research. The policy change also transformed ASEEES into a conduit that connected graduate students to others in the field who share similar interests, thus helping junior scholars to build a network of colleagues. Additionally, the Association has made significant strides to attract international participants, in particular scholars from Russia, Eastern Europe, and Eurasia, offering discounted membership and registration fees. Host cities on the East Coast, such as Boston, Philadelphia, and Washington, DC, or major transportation hubs, such as Chicago, would make it easier and less costly for international participants to attend the conference, which is one possible reason for the trend of holding the convention in these cities multiple times in recent and future years. Although gone are the days of holding the conference in smaller Midwestern US cities or certain exotic places such as Asilomar, California, Boca Raton, Florida, or Banff, Alberta, Canada, the new trend of holding the convention in large metropolitan areas with large international airports would make it less complicated, less costly, and more accessible to a more diverse group of scholars, in order to engage in open scholarly dialogue, which is the essence of the convention in the first place. ${ }^{36}$

\section{Diversity of Sessions by Discipline}

The third case study analyzes the diversity of presentations based on academic discipline. The distribution of disciplines represented by the list of conference sessions in ASEEES programs 2012-2015 were analyzed. ${ }^{37}$ Data was extracted from the ASEEES online searchable programs, which includes a list of subjects or disciplines under the heading Unit Designation (Table 1). The number of sessions per Unit Designation were compiled for each year that was available (2012-2015). Within the system, session organizers select the Unit Designation for his or her session. The Interdisciplinary unit designation is available for sessions that cover more than one discipline. Disciplines that included sub-divisions (history and literature) were compressed into one category. Several other unit designations that were closely related were also compressed in order to view the distribution among broader disciplinary categories. For example, Jewish Studies

\footnotetext{
${ }^{36}$ It would be interesting to compare membership with conference participation in order to get a sense of what percentage of members actively attend the convention each year.

${ }^{37}$ When I attempted to compile data from the paper programs, I soon realized that data extracted from the paper programs would be inconsistent with data from the online system. In the latter (online program systems) the panel organizer selected the Unit Designation, whereas in the former (paper programs), the subject classification would be designated by me. Therefore, in order to inconsistent data, this case study was limited to the four years (20122015) for which data was readily available in the ASEEES online program system.
} 
was combined with Religion / Philosophy; Comparative Politics was combined with International Relations / Security, / Foreign Policy into one category for Political Science; and Language, Literature, and Linguistics were also merger. Although it might seem counter intuitive to a discussion about diversity to combine Unit Designations, this case-study strives to be consistent by analyzing broad disciplinary categories, since data for sub-disciplines is only available for handful of disciplines.

Although four years of data are insufficient to draw strong conclusions, some patterns did emerge. Figure 5 shows the distribution of ASEEES conference sessions by discipline from 20122015. Tables 2 and 3 provide a breakdown of the numbers and percentages by year.

\begin{tabular}{|l|}
\hline Unit Designations for ASEEES Convention Sessions \\
\hline Anthropology \\
Arts/Film/Electronic Media \\
ASEEES \\
Comparative Politics \\
Economic History / Transition Issues / Emerging Markets \\
Gender Studies \\
Geography \\
History: Central and Southeast Europe, Pre-1918 \\
History: Central and Southeast Europe, Since 1918 \\
History: Russian and Eurasian to 1800 \\
History: Russian and Eurasian, 1800-1924 \\
History: Russian and Eurasian, since 1924 \\
Interdisciplinary \\
International Relations / Security Studies / Foreign Policy \\
Jewish Studies \\
Library / Information Sciences \\
Linguistics / Language Pedagogy \\
Literature: Comparative \\
Literature: Russian \\
Literature: Non-Russian \\
Religion / Philosophy \\
Sociology
\end{tabular}

Table 1. Unit Designations are based on the 2015 ASEEES Online Program System 


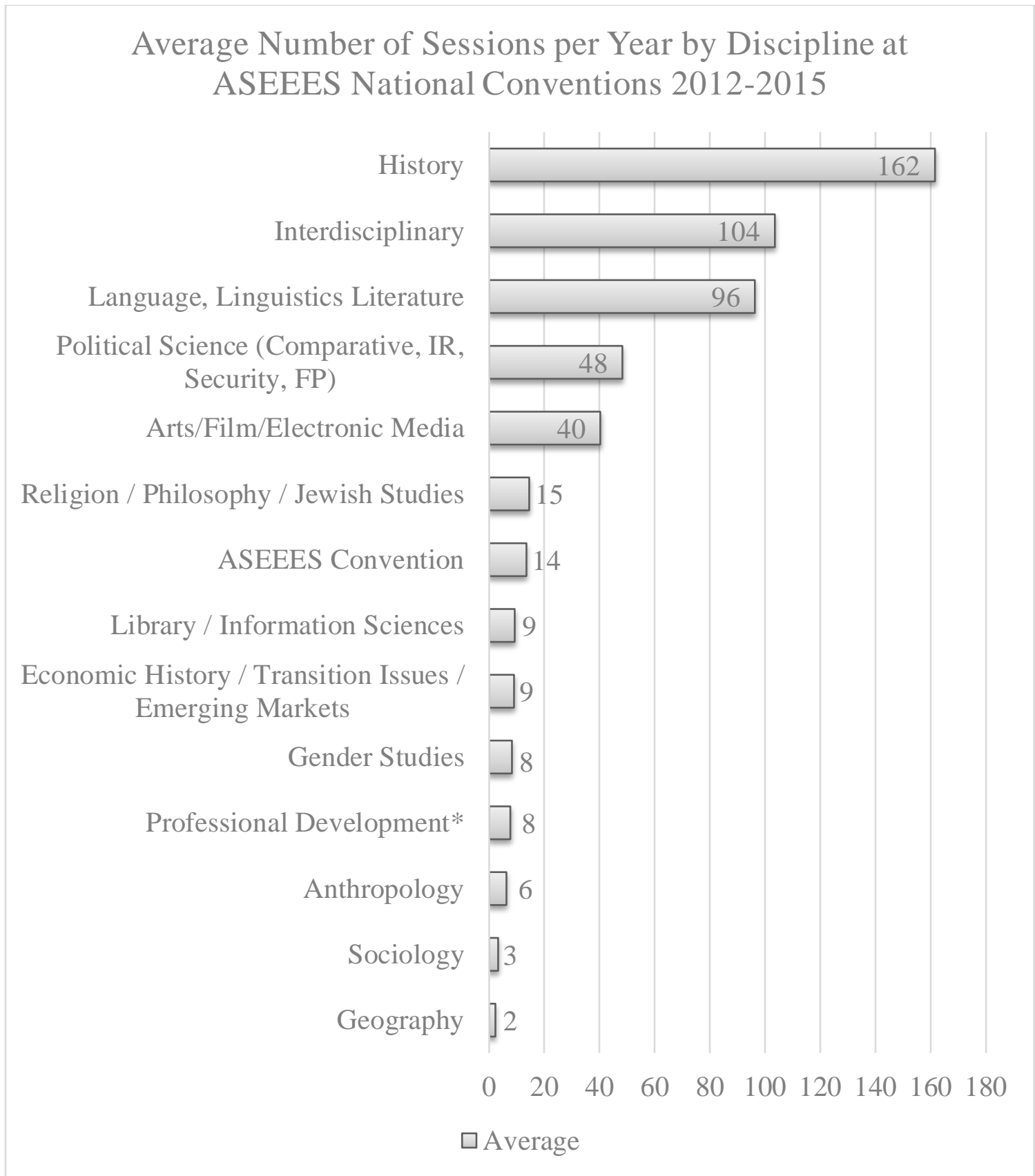

Figure 5: Average Number of Sessions per Year by Discipline at ASEEES National Conventions 2012-2015, (*Professional Development sessions is a 3-year average because data was available for 2013-2015 only). 


\begin{tabular}{|l|r|r|r|r|r|r|}
\hline Number of Sessions by Discipline at ASEEES National Conventions 2012-2015 \\
\hline Discipline & $\mathbf{2 0 1 2}$ & $\mathbf{2 0 1 3}$ & $\mathbf{2 0 1 4}$ & $\mathbf{2 0 1 5}$ & Average & Percent \\
\hline History & 147 & 175 & 129 & 195 & 162 & $30.8 \%$ \\
\hline Interdisciplinary & 101 & 100 & 105 & 108 & 104 & $19.8 \%$ \\
\hline Language, Linguistics Literature & 93 & 105 & 80 & 107 & 96 & $18.4 \%$ \\
\hline Political Science (Comparative, IR, Security, FP) & 43 & 51 & 43 & 56 & 48 & $9.2 \%$ \\
\hline Arts/Film/Electronic Media & 35 & 51 & 34 & 41 & 40 & $7.7 \%$ \\
\hline Religion / Philosophy / Jewish Studies & 17 & 9 & 14 & 18 & 15 & $2.8 \%$ \\
\hline ASEEES Convention & 4 & 22 & 18 & 10 & 14 & $2.6 \%$ \\
\hline Library / Information Sciences & 9 & 10 & 8 & 10 & 9 & $1.8 \%$ \\
\hline Economic History/Transition Issues/Emerging Markets & 7 & 9 & 8 & 12 & 9 & $1.7 \%$ \\
\hline Gender Studies & 7 & 5 & 12 & 9 & 8 & $1.6 \%$ \\
\hline Professional Development* & & 9 & 6 & 8 & 8 & $1.5 \%$ \\
\hline Anthropology & 1 & 6 & 9 & 9 & 6 & $1.2 \%$ \\
\hline Sociology & 1 & 3 & 3 & 6 & 3 & $0.6 \%$ \\
\hline Geography & 2 & 1 & 5 & 1 & 2 & $0.4 \%$ \\
\hline Total & 467 & 556 & 474 & 590 & 524 & $100 \%$ \\
\hline
\end{tabular}

Table 2: Number of Sessions by Discipline at ASEEES National Conventions 2012-2015

\begin{tabular}{|l|r|r|r|r|r|}
\hline Percent of Sessions by Discipline at ASEEES National Conventions \\
\hline Discipline & $\mathbf{2 0 1 2}$ & $\mathbf{2 0 1 3}$ & $\mathbf{2 0 1 4}$ & $\mathbf{2 0 1 5}$ & Average \\
\hline Anthropology & $0.2 \%$ & $1.1 \%$ & $1.9 \%$ & $1.5 \%$ & $1.2 \%$ \\
\hline Arts/Film/Electronic Media & $7.5 \%$ & $9.2 \%$ & $7.2 \%$ & $7.0 \%$ & $7.7 \%$ \\
\hline ASEEES Convention & $0.9 \%$ & $4.0 \%$ & $3.8 \%$ & $1.7 \%$ & $2.6 \%$ \\
\hline Economic History / Transition Issues / Emerging Markets & $1.5 \%$ & $1.6 \%$ & $1.7 \%$ & $2.1 \%$ & $1.7 \%$ \\
\hline Gender Studies & $1.5 \%$ & $0.9 \%$ & $2.5 \%$ & $1.5 \%$ & $1.6 \%$ \\
\hline Geography & $0.4 \%$ & $0.2 \%$ & $1.1 \%$ & $0.2 \%$ & $0.4 \%$ \\
\hline History & $31.5 \%$ & $31.6 \%$ & $27.4 \%$ & $33.4 \%$ & $30.8 \%$ \\
\hline Interdisciplinary & $21.7 \%$ & $18.1 \%$ & $22.3 \%$ & $18.5 \%$ & $19.8 \%$ \\
\hline Language, Linguistics Literature & $20.0 \%$ & $19.0 \%$ & $17.0 \%$ & $18.3 \%$ & $18.4 \%$ \\
\hline Library / Information Sciences & $1.9 \%$ & $1.8 \%$ & $1.7 \%$ & $1.7 \%$ & $1.8 \%$ \\
\hline Professional Development* & $0.0 \%$ & $1.6 \%$ & $1.3 \%$ & $1.4 \%$ & $1.5 \%$ \\
\hline Political Science (Comparative, IR, Security, FP) & $9.2 \%$ & $9.2 \%$ & $9.1 \%$ & $9.6 \%$ & $9.2 \%$ \\
\hline Religion / Philosophy / Jewish Studies & $3.6 \%$ & $1.6 \%$ & $3.0 \%$ & $3.1 \%$ & $2.8 \%$ \\
\hline Sociology & $0.2 \%$ & $0.5 \%$ & $0.6 \%$ & $1.0 \%$ & $0.6 \%$ \\
\hline Total & $100 \%$ & $100 \%$ & $100 \%$ & $100 \%$ & $100 \%$ \\
\hline
\end{tabular}

Table 3: Percent of Sessions by Discipline at ASEEES National Conventions 2012-2015 


\begin{tabular}{|l|l|l|}
\hline Number of sessions & Percent & Disciplines \\
\hline Over 162 sessions & $>30 \%$ & History (30.8\%) \\
\hline 69-104 sessions & $18-20 \%$ & Interdisciplinary (19.8\%), Language/Linguistics/Literature (18.4\%) \\
\hline 14-15 sessions & $7-10 \%$ & Political Science (9.2\%) Arts / Film / Electronic Media (7.7) \\
\hline Under 10 sessions & $<3 \%$ & All other disciplines (.4\% -2.8\%) \\
\hline
\end{tabular}

Table 4: Distribution of Sessions

Based on the average number of sessions per discipline per year, the disciplines seem to fall into four tiers identified below (Table 4). History stands at the top as the dominant discipline at the conference, accounting for nearly one-third (30.8\%) of all conference sessions with 162 sessions on average. The second tier consists of two categories, Interdisciplinary at 104 sessions and onLanguage / Linguistics / Literature at 96 sessions on average. Combined with Interdisciplinary (19.8\%) and Language / Linguistics / Literature (18.4\%) sessions, the top three categories represent nearly $70 \%$ of all ASEEES conference sessions. The third tier shows a significantly lower number of sessions per year on average: Political Science accounted for 46 sessions, and Arts / Film / Electronic Media accounted for 40 sessions, comprising 9.2\% and 7.7\% respectively. The nine remaining disciplines fall into the last group, in which each discipline accounts for less than $3 \%$ of ASEEES conference sessions per year. Anthropology and Sociology, although a small percentage of the total, have demonstrated steady growth since 2012. The number of Anthropology sessions grew from 1 session in 2012 to 9 sessions in 2015 (a nine-fold increase); ${ }^{38}$ and the number of Sociology sessions grew from 1 session in 2012 to 6 sessions in 2015 (a six-fold increase).

As was mentioned above, ASEEES recently changed its policy and began accepting submissions of individual papers. Although it seems plausible that this policy change could have contributed to the increase in anthropology and sociology sessions in recent years, data about individual paper submission would be needed to confirm or refute this hypothesis. An analysis of the papers that were submitted individually and then organized into sessions would provide some evidence on the impact of the ASEEES policy change. A broader question is whether the distribution of sessions by discipline in this study is a reflection of the field Slavic \& Eurasian studies in the U.S. and in North America more broadly. ${ }^{39}$

The distribution of sessions by discipline implies that the ASEEES national convention is a major conference for S\&E historians as well as language, literature and linguistics specialists. The convention seems to be somewhat important for political scientists, and art / film / media specialists who study the S\&E regions. ${ }^{40}$ With regard to the number of scholars in the other disciplines (under

\footnotetext{
${ }^{38}$ The increase in the number of anthropology sessions is good news for anthropologists. See article by Katherine Verdery, former AAASS President, "Bringing the Anthropologists (Back) In" discusses the value that Anthropologists bring to the Association, NewsNet, v. 46, n. 1 (January2006): 1-11.

${ }^{39}$ While the number of ASEEES members and convention attendees from outside the US \& Canada grows, the bulk of conference participants are based in North America.

${ }^{40}$ According to a 2008 article in NewsNet, AAASS seems to have lost some importance among political scientists, as the number of political scientists in ASEEES showed a steady decline from 1997-2007. See Anna Grzymala-Busse and
} 
3\% of sessions), whose work relates to Slavic and Eurasian studies, one could make two inferences from the data: 1) S\&E studies scholars in these disciplines tend to participate in the conferences of their respective disciplines; or 2) there are relatively few S\&E studies scholars who work in these disciplines. In library and information science, for example the ASEEES national convention is the most important conference for librarians with responsibility for managing collections; whereas S\&E catalogers are more likely to attend American Library Association (ALS) meetings because of the active cataloging committees within ALA. ${ }^{41}$ Librarians who cover other disciplines in addition to S\&E studies among them are more likely to attend ALA in order to network with librarians in those other disciplines.

The one discipline that has maintained the most consistent percentage of sessions at ASEEES conferences is Library and Information Sciences (LIS). Over the four year period that was analyzed, the number of LIS sessions as a percentage of the total sessions, varies by only two tenths of one percent (.2\%). The reason for this consistency is simple. Because librarians have many committee meetings to attend at ASEEES, the ASEEES Committee on Libraries and Information Resources (CLIR) encourages librarians not to exceed 8-10 sessions per conference in order to avoid scheduling conflicts between sessions and committee meetings. The distribution of LIS sessions by topic from 2007-2015 reveals an emphasis on collections, digitization and digital resources, and to a lesser extent publishing (Figure 6). One could argue that this distribution reflects the relative importance that library colleagues place on the different aspects of librarianship in S\&E studies. In area studies librarianship, collections have always dominated the discussion. When one considers that digitization and digital resources are essentially digital collections, the number of ASEEES sessions dedicated to collections in all formats comprised nearly half (45\%) of all LIS sessions over the past 9 years. One could argue that other categories also deal with collections, only to a lesser extent; however the connection is not as strong.

The one topic that seems to be neglected is Reference, Instruction, and Outreach (RIO). This phenomenon is surprising given the amount of time librarians dedicate to helping others use the collections. So why don't we talk more about RIO? The good news is that discussions about RIO are increasing. During 2012-2015, four out of five sessions dedicated to RIO took place. Additionally, ASEEES CLIR recently established a Task Force on Education and Outreach to investigate and promote instruction-related activities, such as ASEEES webinars. The Task Force has committed to present two of the four ASEEES webinars per year. As these discussions and activities expand, it seems likely that the Task Force will form a new CLIR subcommittee in order to meet growing needs and interests.

\footnotetext{
Natalie Koch, "Where Have the Political Scientists Gone?" AAASS Initiative to Reverse the Relative Decline in Membership among Political Scientists. NewsNet, v. 48, n. 2 (March 2008): p. 1.

${ }^{41}$ The ASEEES Committee on Libraries and Information Resources (CLIR) has Subcommittees on Collection Development, Copyright Issues, Digital Projects, and Slavic and East European Materials Project, all of which are related to collections (https://sites.google.com/site/aseeesclir/); but does not have a cataloging subcommittee. The Automated Bibliographic Control (cataloging) committee for S\&E studies belongs to the Slavic and East European Section of ACRL (https://sites.google.com/site/seesliborg/).
} 


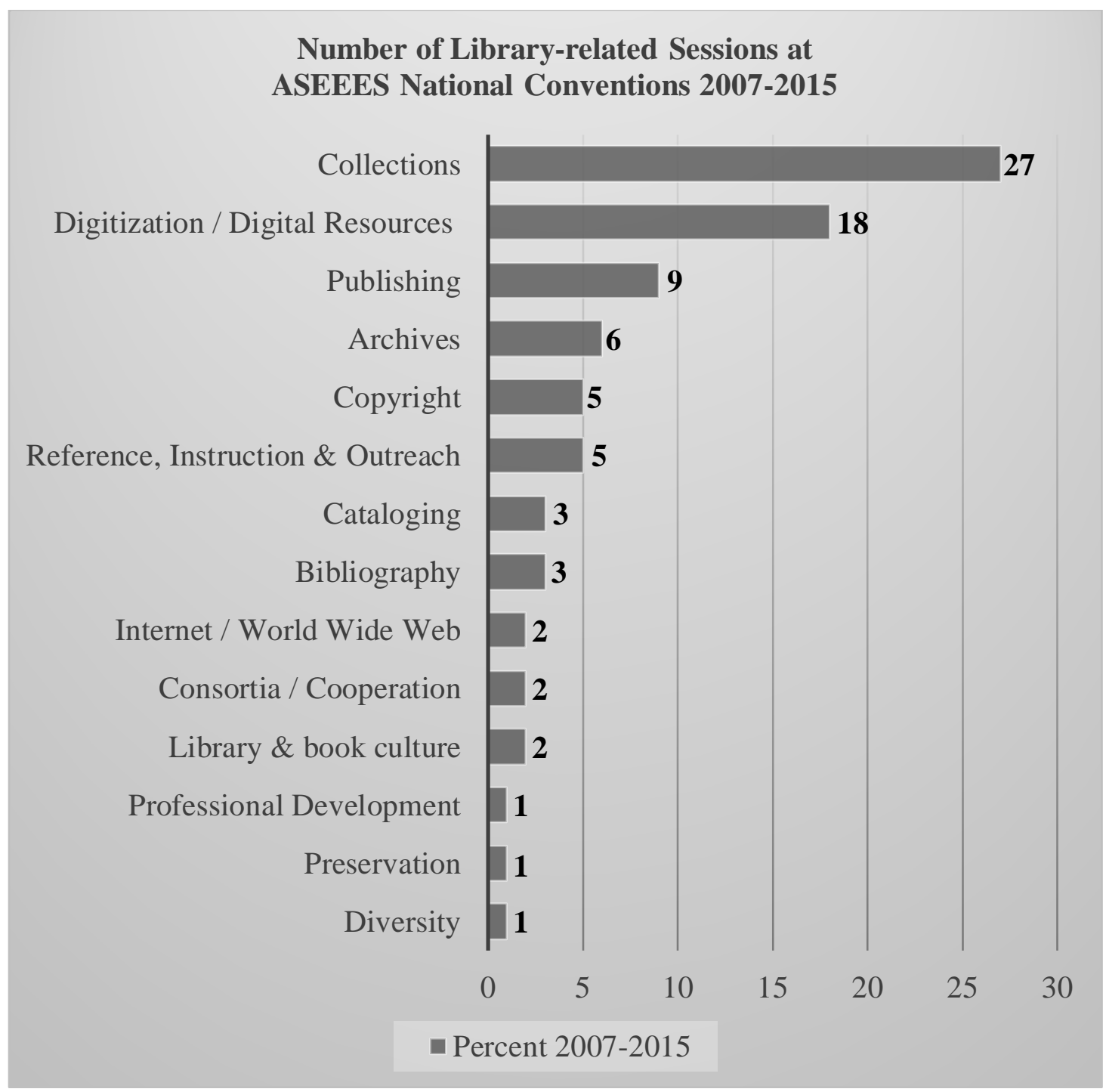

Figure 6: Number Library-related Sessions at ASEEES National Conventions 2007-2015

\section{Institutional Diversity}

Institutional diversity in Slavic and Eurasian studies is the fourth and final case study in this investigation. The distribution of institutions represented by ASEEES session participants was examined using the ASEEES the online programs 2012-2015. Data can be filtered by an institution's location, such as state, region, or country; by size of the institution (FTE); or by private or public institution. Unfortunately, the total number of institutions represented by ASEEES convention participants from 1964-2015 is beyond the scope of this case study. A broad and complex demographic analysis would require substantial assistance from ASEEES staff. This investigation utilizes a smaller subset of data for analysis. The subset consists of ASEEES participants from institutions with a Title VI National Resource Center (NRC) for Russia, East 
Europe, and Eurasia. (REEE) $)^{42}$

REEE National Resource Centers were selected as a limiting factor because these centers have influenced the evolution of Slavic \& Eurasian studies over the past six decades. The NRCs are supported by Title VI funds from the Department of Education and represent a substantial investment in the study of the region by the Federal Government. ${ }^{43}$ Backed by the money and credit of the United States government, REEE NRCs at hosting institutions represent hubs of scholarly activity, and comparative analysis of an institution's representation at ASEEES national conventions provides one measurement of the impact of government funding on the activity level in S\&E studies at institutions with REEE NRCs.

Data were collected using the ASEEES online searchable program and provide a snapshot of the distribution of ASEEES participation by institution. ${ }^{44}$ The process involved searching the online program by institution under the People tab and then compiling the number of participants from each institution that hosts a REEE NRC. The data do not differentiate between the academic classification of individuals (e.g. faculty, staff, and student). Figure 7 compares the level of engagement, measured by participation in ASEEES national conventions, among scholars affiliated with REEE NRCs at fifteen institutions nationwide.

The distribution of participants at ASEEES national conventions from institutions with REEE NRCs can be divided into four tiers (Figure 7). Harvard University stands alone the top, boasting a four-year average of 45 session participants annually. The list of institutions in the second tier descends gradually by just one or two participants from 34 to 27 participants and includes six universities: Wisconsin-Madison (34), Pittsburgh (32), California-Berkeley (30), Illinois-Urbana-Champaign (29), Indiana (29) ${ }^{45}$, and Michigan (27). The list of institutions in the third tier also descends gradually, from 21 to 14 session participants, and also includes six universities: Georgetown (21), Chicago (20), Stanford (19), Ohio State (19), UNC-Chapel Hill (16), and Kansas (14). The range between the lowest and the highest number of participants in both the second and third tiers is seven participants. The final tier consists of two universities, the University of Washington (9) and Duke University (6). The distribution shown in Figure 7 is one measurement of the level of recent (2012-2015) scholarly engagement at institutions with REEE NRCs. This snapshot is just one small piece of a much larger puzzle. Although the data do not distinguish between practicing, established scholars and graduate students, one could logically infer that a portion of the participants would be graduate students, the majority probably being advanced (Ph.D. seeking) graduate students. Potentially, the higher the number of total participants from a given institution, the higher the number of graduate student participants from that institution. A strong contingent of graduate student participants would also point toward a

\footnotetext{
42 “National Resource Centers Grantees and Funding for FY 2010 and Estimate for FY 2011-2013” http://www2.ed.gov/about/offices/list/ope/iegps/nrcflasgrantees2010-13.pdf, Accessed June 3, 2015.

${ }^{43}$ For more information see: "Title VI Programs: Building a U.S. International Education Infrastructure," U.S. Department of Education, http://www2.ed.gov/about/offices/list/ope/iegps/title-six.html, Accessed June 3, 2015. ${ }^{44}$ The system was upgraded in 2014, so the interface for 2012-2103 differs from the current interface.

${ }^{45}$ Indiana University boasts two NRCs related to S\&E studies, the Russian and East European Institute (REEI), and the Inner Asian and Uralic National Resource Center (IAUNRC).
} 
thriving graduate program in S\&E studies. Data on the actual number of graduate student session participants from each institution would be necessary to confirm this assertion. Unfortunately this data is not readily available from ASEEES online conference programs.

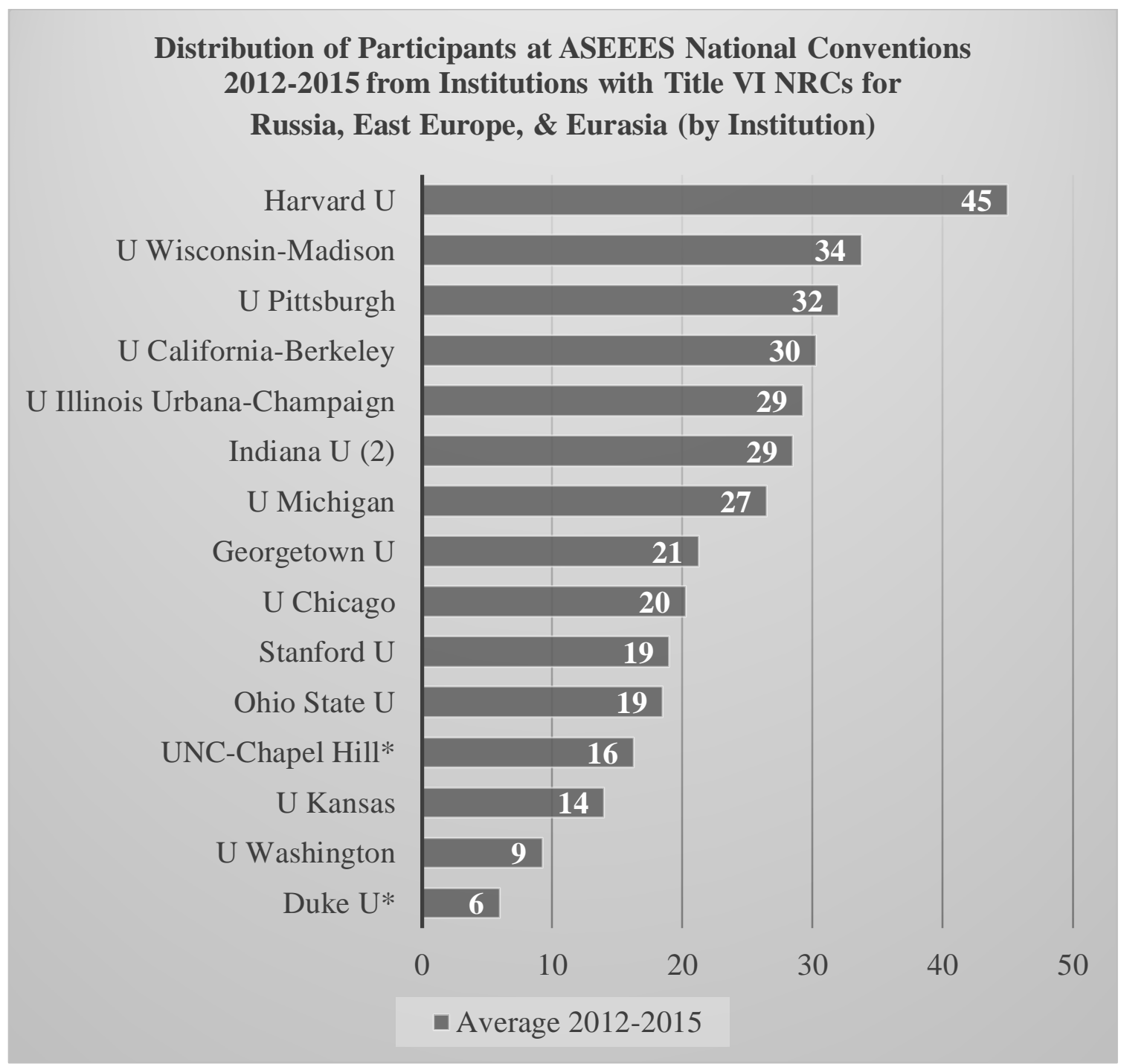

Figure 7: Distribution of Participants at ASEEES National Conventions 2012-2015 from Institutions with Title VI NRCs for Russia, East Europe, \& Eurasia. ${ }^{46}$ (*UNC-Chapel Hill and Duke U share a combined NRC for Slavic and Eurasian studies). ${ }^{47}$

\footnotetext{
${ }^{46}$ The number of participants is rounded to the nearest whole number. Hence, Illinois and Indiana both show 29, but the percentage for Illinois is slightly higher than Indiana's percentage. The same goes for Stanford and Ohio State, both of which show 19 participants, but Stanford's' percentage is slightly higher than the percentage for Ohio State.

${ }^{47}$ Even though UNC-Chapel Hill and Duke U share a combined NRC, it was decided to list them separately in order to be consistent because they are separate institutions.
} 
Not all graduate students in S\&E programs, however, participate in professional conferences such as ASEEES. An institution may have a thriving M.A. program in which graduate students choose careers outside the academy. Many graduate students in S\&E studies will go on to professional careers without having presented a paper at a professional conference, yet anecdotal evidence suggests that the number of graduate student participants at ASEEES national conventions appears to be increasing. For example, in recent years, the number of graduate students from the University of Kansas who gave or will give presentations at ASEEES conventions has increased dramatically since 2012 and has remained steady for three years (Figure 8). Some of the presenters were M.A. students in Russian, East European, and Eurasian Studies, while others were Ph.D. candidates from a variety of disciplines (e.g., geography, history, language $\&$ literature). Conference presentations continue to be a transitional step for advanced graduate students preparing to enter the academy, but recently a growing number of graduate students pursuing non-teaching careers have begun to recognize the value of presenting their research at professional conferences. Not only do their conference presentations demonstrate their knowledge and skills to potential employers, but if these individuals later choose to return to the academy, their past experience presenting at conferences provides a foundation for future academic work.

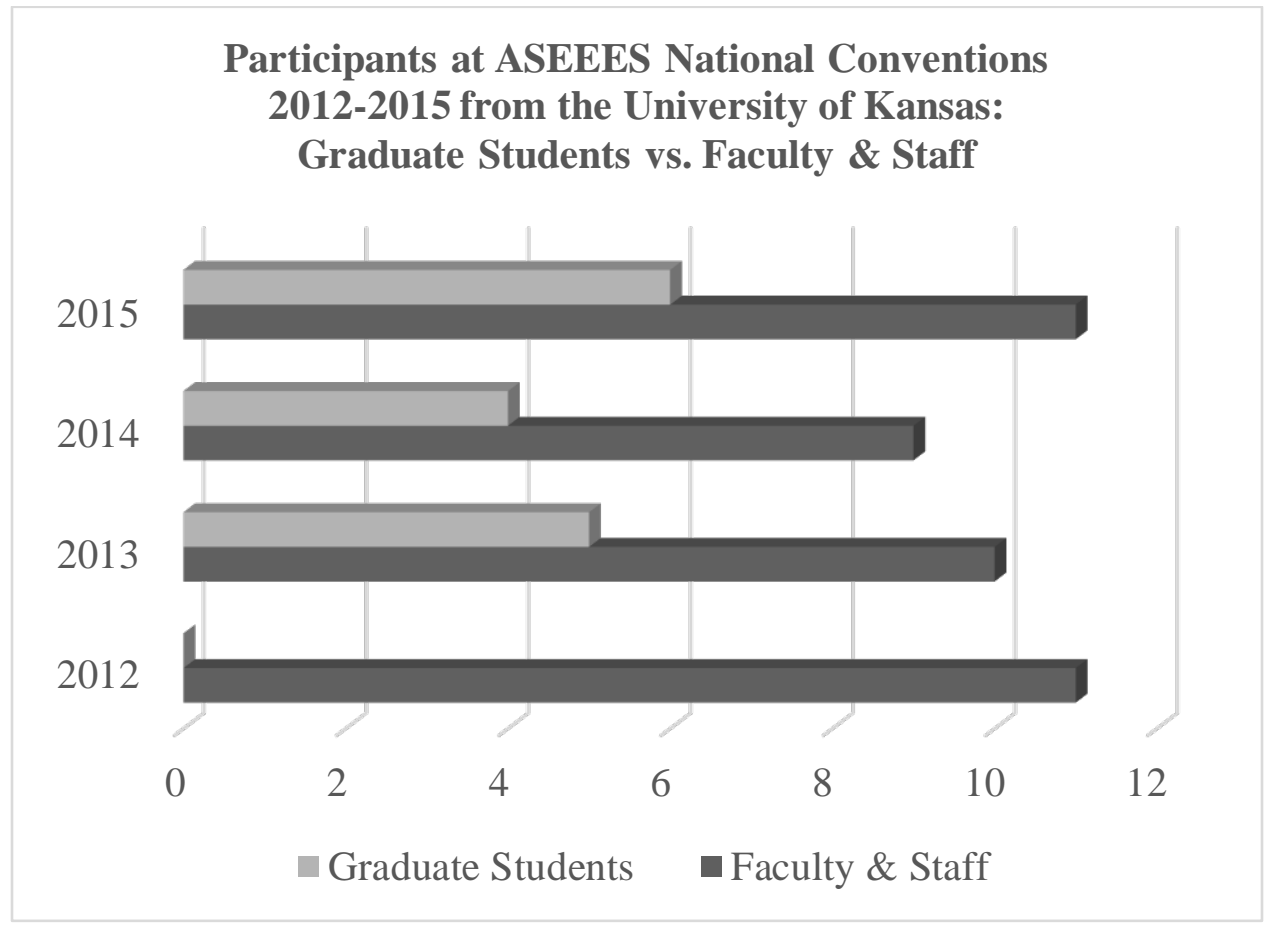

Figure 8: Participants at ASEEES National Conventions 2012-2015 from the University of Kansas: Graduate Students vs. Faculty \& Staff. 
The distribution of participants from REEE NRC-affiliated institutions can also be analyzed for geographical diversity. ${ }^{48}$ Figure 9 shows the geographical diversity of institutions with REEE NRCs. The Midwest has the largest number of institutions with NCRs (7) for Russia, East Europe, and Eurasia, followed by the Northeast (3), the West (3), and the South (1). Given this fact, one would expect the Midwest to also have the highest number of participants, by region, at ASEEES conventions, which is indeed the case. The American heartland boasts the highest level of engagement at recent ASEEES national conventions by individuals from institutions with REEE NRCs (Figure 10). According to Figure 10, half of the participants (181, $50 \%$ ) in this data set hail from Midwestern institutions while the other half (182) reside in the Northeast (110, 30\%), West (44, 12\%), and South (28, 8\%) regions. While the top institution, Harvard University, as measured by ASEEES session participation (Figure 8), belongs to the Northeast region, most of the second tier institutions (4 out of 6 ) are located in the Midwest region. Likewise, half of the institutions (3 out of 6) in the third tier are also located in the Midwest region. The two institutions in the fourth tier Midwest region.

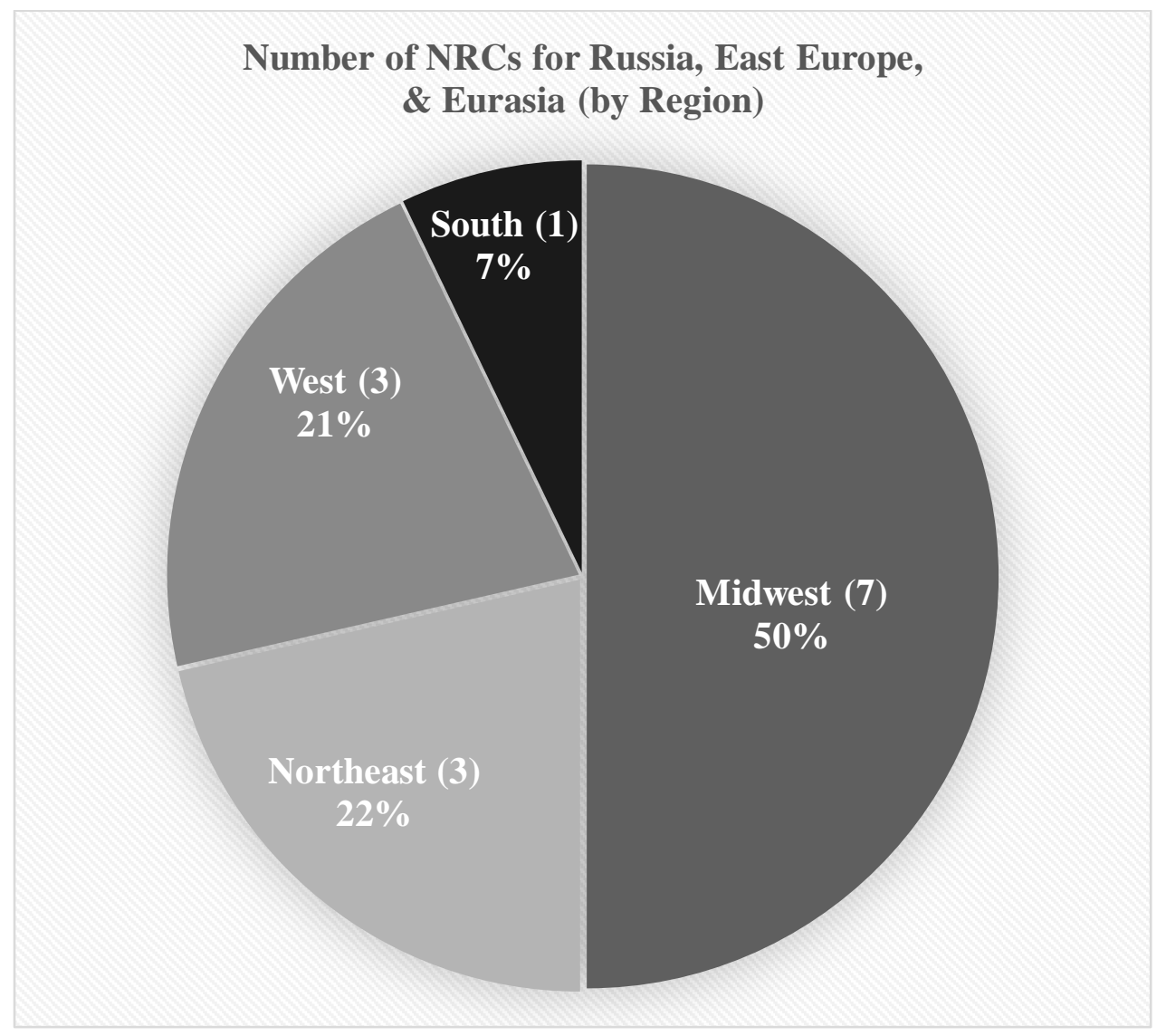

Figure 9: Number of NRCs for Russia, East Europe, \& Eurasia (by Region).

\footnotetext{
${ }^{48}$ Regional divisions are based on the United States Census Regions and Divisions of the United States. See map at http://www2.census.gov/geo/pdfs/maps-data/maps/reference/us regdiv.pdf, Accessed June 3, 2015.
} 


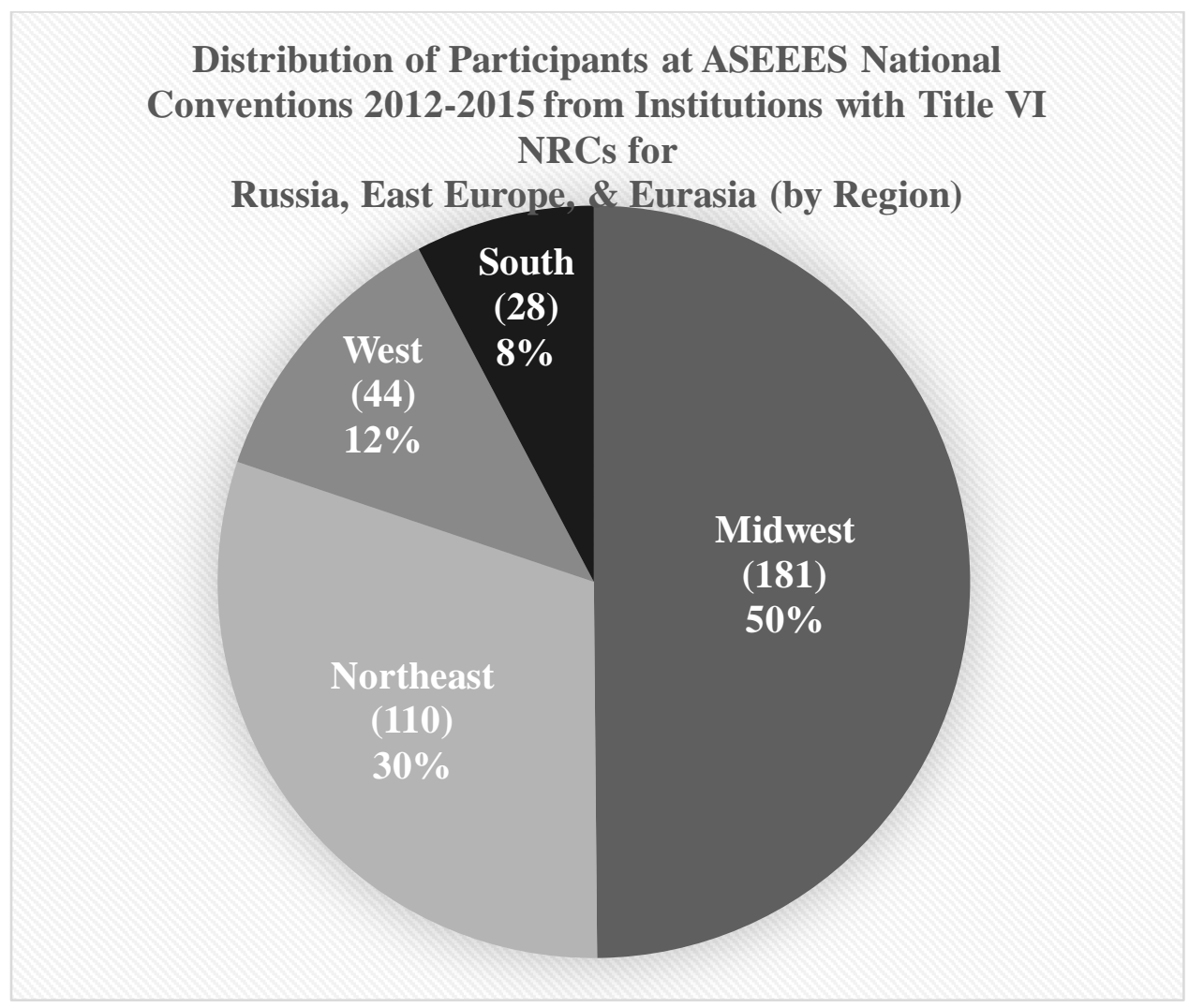

Figure 10: Distribution of Participants at ASEEES National Conventions 2012-2015 from Institutions with Title VI NRCs for Russia, East Europe, \& Eurasia: by Region

The two institutions in the fourth tier belong to the West and the South. Obviously, the number of participants from the South region is lower because the South Region has only one REEE NRC. ${ }^{49}$ It would be useful to compare the regional distribution of institutions represented for all ASEEES session participants in order to determine whether the regional pattern of total participation mirrors the regional pattern of REEE NRC-affiliated participation. ${ }^{50}$ Unfortunately such an analysis is beyond the scope of this article.

\footnotetext{
${ }^{49}$ The one NRC in the South region is shared by two institutions, UNC-Chapel Hill and Duke U.

${ }^{50}$ The comparison would require assistance from the Association's staff to extract data from ASEEES conference statistics.
} 


\section{Conclusions}

Data from this investigation corroborate other data to show that gender diversity within the field of S\&E studies has changed significantly over the past 40 years. The number of men and women session participants at ASEEES conventions is virtually equal, and this majority in all likelihood reflects the changing landscape of the field of Slavic and Eurasian studies. Women have long been active in the disciplines of language, literature, and art, but in recent decades an increasing number of women have entered other disciplines (e.g., economics, geography, history, mathematics, political science, philosophy, religion, science and technology, etc.) that were formerly populated mostly by men. One need only look at departmental webpages at North American institutions, in particular, to see the similar numbers of men and women in these disciplines, and there is no reason to believe that this trend will not continue.

As the field of Slavic and Eurasian studies evolves, ASEEES will also evolve. Although ASEEES conventions involve a broad range of disciplines, the distribution of sessions continues to be dominated by history, interdisciplinary studies, and language and literatures. The strong presence of interdisciplinary sessions itself is a sign of diversity, a sign that many ASEEES participants reach outside their own discipline to explore connections with other disciplines. In recent years ASEEES conventions have attracted a growing number of sessions from disciplines (anthropology, sociology) previously under-represented within the Association. Hopefully, science and technology will soon emerge as a disciplinary category at ASEEES conventions since science and technology has been driving radical societal changes for the past two decades; and the field of science and technology studies has been experiencing considerable growth.

Over the past two decades declining enrollments and the closing of programs in Slavic \& Eurasian studies also have been a concern for ASEEES and for everyone in the field. During this period, the field has witnessed a contraction of U.S. Government funding for REEE programs. Whereas the amount of funds distributed to Title VI National Resource Centers (NRC) was cut by nearly half in 2012, the latest grant competition for Title VI funds witnessed a reduction in the number of REEE NRCs nationwide. The University of Kansas, Georgetown, Michigan, North Carolina at Chapel Hill and Duke were the latest casualties of this contraction. Is it a coincidence that three of the universities which lost their NRCs (Kansas, UNC-Chapel Hill, and Duke) show a lower level of scholarly engagement at recent ASEEES conferences? Maybe, or maybe not since the other two casualties (Michigan and Georgetown) showed comparatively high engagement at recent ASEEES conference. As mentioned before, this measurement is just one tiny piece of a larger and more complex puzzle.

Diversity in Slavic and Eurasian studies can take many forms. The variety of topics presented at ASEEES national conferences is extraordinary. Arguably, one of the reasons that many ASEEES members entered the field is because the fell in love with a particular Slavic or Eurasian culture or cultures and decided to dedicate their lives to studying aspects of those cultures. The aspects of diversity discussed in this investigation represent just a few observations that contribute to the discussion about diversity in Slavic \& Eurasian studies. 


\section{4-2015 ASEEES National Convention Participants: by Location and Year}

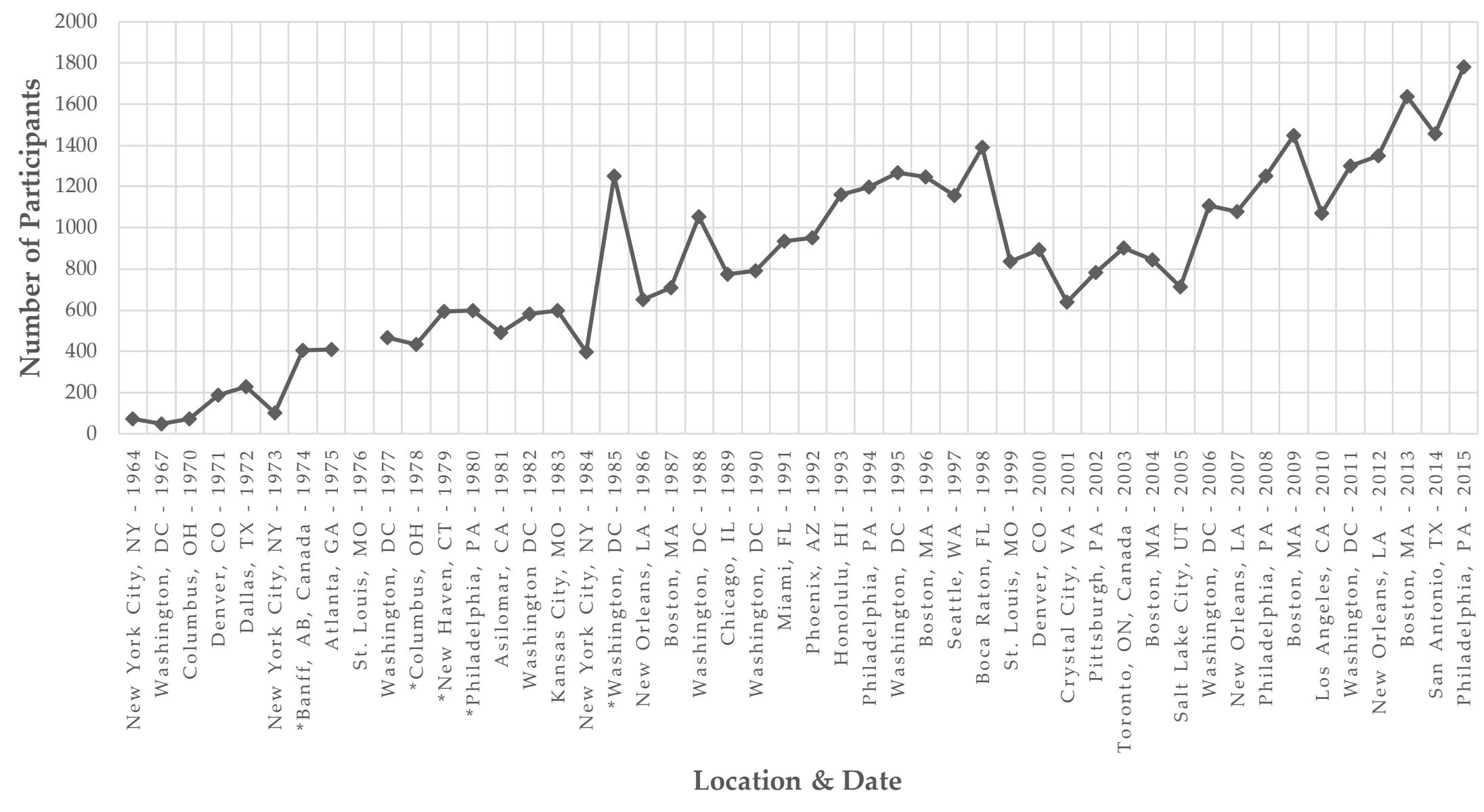

Figure 3: Number of Conference Participants at ASEEES National Conventions 1964-2015: by Location and Year (*Indicates a joint conference with one or more associations (e.g., ICSEES, Central Slavic Association, Midwest Slavic Association, etc.). 